\title{
TAHSP:-
}

The Internet Joưnal of Allied Health Sciences and Practice

A Peer Reviewed Publication of the College of Health Care Sciences at Nova Southeastern University

Dedicated to allied health professional practice and education

http://ijahsp.nova.edu Vol. 12 No. 4 ISSN 1540-580X

\section{Questions and Decisions: Application of a Cyclical Model for Program Assessment}

\author{
Cathy Bieber Parrott, PT, MS 1 \\ Marleen lannucci, $\mathrm{PT}, \mathrm{PhD}^{2}$
}

1. Assistant Professor, Department of Physical Therapy, Youngstown State University, Youngstown, Ohio

2. Professor, Department of Physical Therapy, Youngstown State University, Youngstown, Ohio

United States of America

CITATION: Bieber Parrott C, lannucci M. Questions and Decisions: Application of a Cyclical Model for Program Assessment. The Internet Journal of Allied Health Sciences and Practice. Oct 2014. Volume 12 Number 4.

\begin{abstract}
Purpose: Expectations for public accountability, including accreditation, challenge allied health science educational programs to develop a sound program assessment plan. However, program assessment is often detached from what faculty feel is important. What is needed is a model for assessment that allows faculty to adapt assessment processes so they can ask their own questions and obtain useful findings that guide their decisions about program improvement. The purpose of this paper is to posit our model for program assessment, provide an example of implementation of the model, and discuss its value. Model Description and Implementation: Our proposed model is rooted in the needs assessment frameworks developed by respected experts in higher education program assessment. A goal of our model was to make it less complex than prior models but universally flexible, and to include the 5 elements we deem essential. Method: This paper explains the conceptual basis of the model and describes its two process cycles (questions and decisions), the first of which prompt faculty to ask important assessment questions and identify appropriate methods, data sources and stakeholders for inquiring about the question. The second cycle facilitates faculty to analyze the data and make appropriate decisions about program change. One question about student learning related to decision making is used as an example of the model implementation for program assessment. Results: The model cycles clarified the extent of student and employer perceived needs in clinical decision making. The model also illustrated to faculty how to make decisions about program change and follow with ongoing assessment. The effectiveness of the model to engage faculty in data driven program assessment is discussed. Conclusion: A heuristic assessment model can direct faculty to identify important questions and implement meaningful data collection which leads to focused program decisions. Our model facilitates faculty ownership of crucial questions, guides an assessment process that reveals the extent of program needs, and leads to measured program changes.
\end{abstract}

\section{INTRODUCTION}

In environments of scarce higher education resources, allied health science education programs must show that they can effectively and efficiently prepare students and meet the expectations of others. ${ }^{1,2}$ External calls for accountability emanate from the professions themselves, the health care industry, and society in general to assure academic quality and public protection. ${ }^{3-5}$ Many allied health science programs are accredited, and accreditation criteria also require evidence of academic quality. Additionally, each university has accreditation standards, and allied health science programs are expected to meet these criteria as well. ${ }^{6}$ Accreditation assures the public that quality standards are comparable across higher education institutions. However, each university sets its own mission and vision based on demographics, state priorities, and regional characteristics. Health science programs are expected to be similar to other programs and universities and yet defend its unique professional identity 
and university contribution. ${ }^{7-9}$ Educational programs respond to these many calls for accountability by engaging in program assessment.

Many program chairpersons and faculty remain unclear about how to proceed with assessment or are required to use a predetermined organizational plan. It can be difficult for them to value an assessment process that is seemingly detached from their day-to-day activities. ${ }^{10-12}$ If assessment does not provide meaningful information, faculty are likely to view demands for their involvement as little more than a time-consuming administrative task.13,14 What faculty need is a process that connects assessment accountability to everyday responsibilities. This paper describes the development and implementation of a program assessment model that allows faculty to ask their own questions, collect meaningful data, and generate useful findings to guide their decisions about program improvement.

\section{MODEL DEVELOPMENT}

Some allied health professions offer resources to guide program assessment in the hope that the complexity associated with assessment is simplified. The proposed model is similar to this work by preserving the essentials of connection to program goals, utilization of focused questions, a data-driven process, and the application of results. In contrast, however, the proposed model was developed so assessment can follow, rather than direct faculty interest in improving student learning.

Also informing the proposed model is the literature in higher education that has in recent years moved beyond the "close the feedback loop" concept of using assessment data. Wehlburg suggests an assessment spiraling that will "continually monitor and intentionally increase the quality of each assessment cycle." 15 Wehlburg's notion of transformative assessment stresses the "use of evidence in regular and ongoing decision making."16 Our model similarly adopts the spiral metaphor, but more in an overlapping circular pattern. An initial circle prompts faculty to inquire into their own questions to identify problems, and then join a second circle to make important decisions for solutions. Our model prompts a return to these overlapping circles of questions and decisions for ongoing analysis. Our model is also akin to the assessment spiral of Banta who advocates a double loop of assessment where re-measurements determine if the assessment continues to yield meaningful results. ${ }^{17}$ We agree that repeated measures yield more meaningful data. Our model extends that concept to include repeated measures by different methods, sources, and communities to triangulate the findings.

None of the literature suggested a parsimonious conceptual model with all 5 elements we deemed as essential: use of program goals, faculty engagement, needs assessment, diverse stakeholders, iterative or ongoing process. Therefore, the model described in this paper is based on these 5 elements. Our goal was to provide a less complex model than those found in the literature but universally usable. The purpose of this paper is to posit our model for program assessment, provide an example of model implementation, and discuss its value.

\section{Model Description}

The model initiates with a needs assessment framework. Needs assessment entails an informed description of current and ideal program status to illuminate any gap between them. This gap indicates program need. Rather than proceed with possibly illperceived solutions to resolve a perceived need, our model motivates faculty to ask questions which will define the need and then make informed decisions. The first cycle in the model is titled Questions and the later cycle is Decisions. The Question cycle, shown in Figure 1, contains the elements: varied methods, diverse data sources, and communities of interest. The second cycle, Decisions, has elements of revising questions, raising new questions, and making program changes (Figure 2). The needs assessment framework of the model will be described first, followed by a description of the elements of each cycle. 
Figure 1. Question Cycle

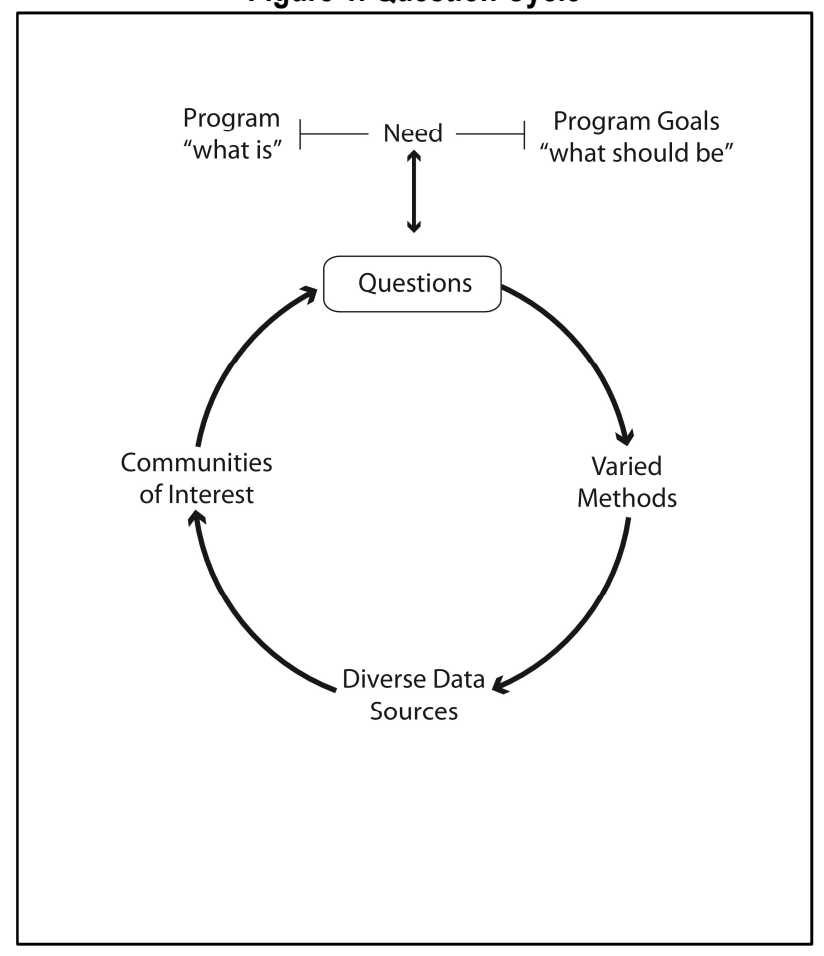

Figure 2. Decision Cycle

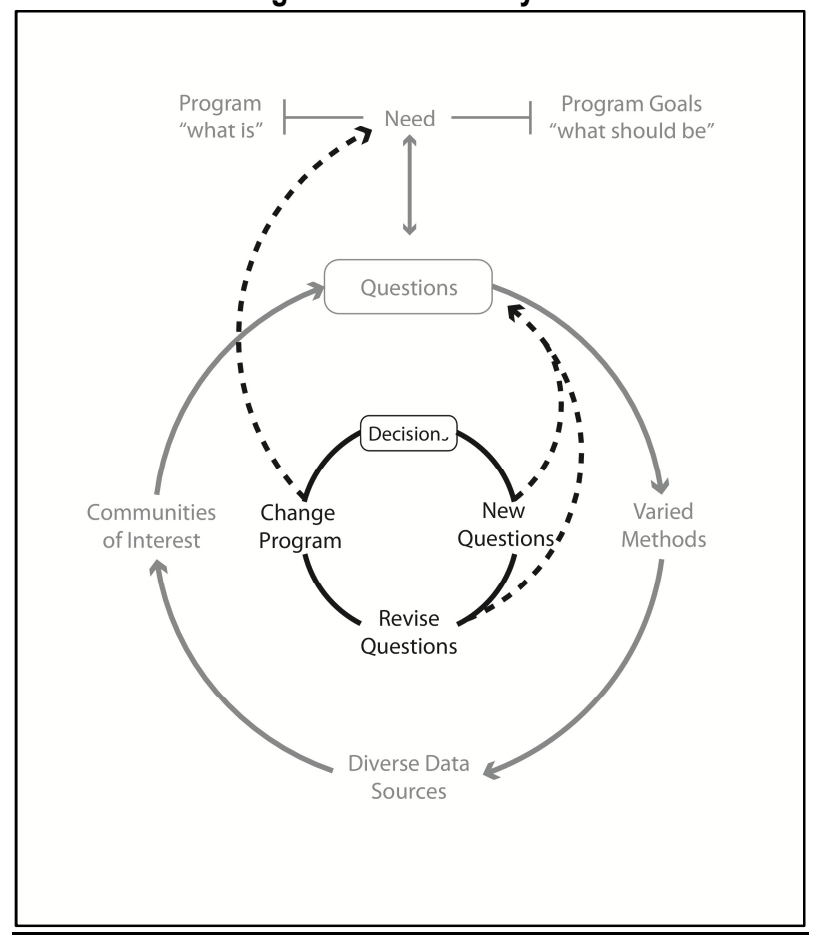

\section{Current Program: "What Is"}

The model requires programs to begin assessment using supporting evidence to document the current status of the program. The current status can be described using the curriculum, department resources, student and faculty profiles, admissions data, and teaching-learning patterns of activity. ${ }^{18,19}$ It is essential for programs to begin with this description of "what is" program status as a basis from which to develop questions that guide program assessment inquiries. When faculty know the current status of 
their program they can ask questions about their own courses and the program in comparison to the profession and the university. Grounding the assessment process in faculty-generated questions provides the ownership and commitment integral to the process and leads to decisions they value. ${ }^{13,14}$

\section{Ideal Program Status: What Should Be}

University and professional expectations set a normative range for programs to operate within but each program sets its own program goals. Program goals are based on the program mission and what the program aspires to. Thus, program goals are the program's own definition of "what should be."11 Methods to help faculty prioritize goals to be assessed may be found in Table 5.1 found in the book "Needs Assessment: Analysis and Prioritization."20 Table 5.2 in the same book provides a template for using criteria such as cost factor and risk when prioritizing goals in more complex situations. Both tables are reproduced in appendix A. Prioritized goals representing the program's aspirations of "what should be" are used by faculty to begin to identify needs.

\section{Program Needs}

Program needs are based on the assumption that the ideal is not yet achieved. In fact, no need exists if the program has achieved its goals completely. The gap between current program status (what is) and program goals (what should be) identifies a program need. ${ }^{21,22}$ The larger the gap, the greater the need. Various needs assessment methods are available that measure and/or describe both the current and ideal status of a particular program component.21,23,24 These methods make explicit the gaps or needs that faculty should inquire about during assessment.

General questions naturally arise when there is an inconsistency between the current status of a program and the program's vision of where it wants to be. These questions are generated when faculty juxtapose the program's profile with accreditation data, discuss the program's progress toward professional vision statements, and the like. Faculty must then focus questions so that specific, not diffuse results are obtained from assessment efforts. To focus questions, faculty can use existing assessment data, accreditation or internal program reviews, impending practice changes and input of past graduates or current employers of graduates. Faculty each contribute based on their roles and responsibilities (e.g., coordinator of clinical education, admissions committee member) or particular expertise (e.g., minority recruitment). A focused question initiates the first cycle of the assessment model, the Question cycle. There are three elements contained in the Question cycle: varied methods, diverse data sources and communities of interest. These three elements are used by faculty to guide implementation of assessment activities.

\section{Question Cycle Element: Varied Methods}

One of the most problematic areas for program assessment is selecting a methodology to obtain data that is consistent with the identified program question. ${ }^{25,26}$ Often, assessment data are obtained by the easiest methods while the most important data for investigating a question may be the most difficult to measure. Questions should drive the method choice so that the information collected conveys the breadth or depth needed. For example, a program in need of a prioritized list of content areas to answer a curriculum question will employ a very different methodology than a program in need of a comprehensive admissions process. For the former issue, a methodology would be needed to combine faculty input into a prioritized list. The magnitude estimation scaling method allows each faculty to rank content areas and then aggregates the individual priorities. A methodology to meet the need for a comprehensive admission process might involve interviewing faculty from comparable institutions to learn how an admission process can meet the needs of both the program and the applicants. Each methodological technique has advantages and disadvantages to consider, but most important is that the choice is appropriate for the question. ${ }^{19,27}$

\section{Question Cycle Element: Diverse Data Sources}

The Question cycle element diverse data sources reminds faculty to consider sources of data beyond the most common. Common data sources include exam scores, number of faculty publications, graduate and/or employer survey responses, graduation/retention rates, program costs over time and changes in resources, etc. Choosing a data source will depend on the assessment question asked and programs should not ignore less-common potential data sources. For example, while tests are a routinely considered data source, questions from later tests can be pre-tested as another data source at the beginning of the course to determine students' knowledge base. Results from this pre-course source may show students already have some content knowledge. The difference between current knowledge and the ideal (100\%) now shows less-than-expected need, resulting in course changes to prevent re-teaching known content. Multiple data sources may be needed to substantiate any finding from a single data source.

\section{Question Cycle Element: Communities of Interest}

Students and faculty are program stakeholders or communities of interest that are often involved in program assessment. ${ }^{28} \mathrm{In}$ addition to the most familiar communities, inclusion of those often neglected may provide unexpected and novel findings. Neglected communities of interest include potential applicants, clients, local policy makers and related-discipline faculty, etc. 6,8

(c) The Internet Journal of Allied Health Sciences and Practice, 2014 
The proposed model prompts utilizing diverse communities of interest to create an evolving layer of participation by important stakeholders in the assessment process.

\section{Decisions: Second Cycle of the Model}

The needs assessment and Questions cycle of the model guides faculty to conduct investigations of meaningful questions but one iteration of the cycle rarely yields clear data that adequately defines an answer to resolve program need. Next-step alternatives are revealed in the second cycle of the model called the Decision cycle shown in Figure 2. The three decision alternatives are: New Questions, Revised Questions, and Change Program. The first two decision alternatives return assessment to the Question cycle, as depicted by the dashed arrows on the right of the Decision cycle. The other decision alternative, Change Program, moves faculty out of the Question cycle to address defined program need. This process is indicated by the dashed arrow on the left of the Decision cycle in Figure 2.

With the assumption that the assessment process will be ongoing and not episodic, there is no incentive to make program changes that may not be successful.29,30 The model prevents a premature change by prompting faculty to consider re-entering the Question cycle rather than move directly to an action for change. The importance of achieving program goals and the realities of scarce resources is incentive for cautious and data-driven program changes. ${ }^{31}$ When the Question cycle findings leave faculty needing more evidence about the extent of the need or wanting additional information to justify program change, choosing Revising Questions and Raising New Questions would be the appropriate decision. The model minimizes the tendency to use initial data to make immediate changes but rather prompts to use data to inform the process until the findings triangulate. Program changes without substantial evidence can seriously disrupt a cohesive program design. Re-entering the question cycle remains a viable and thoughtful decision.

When there is enough evidence to support a decision for program change without further inquiry, faculty should not ignore the data. Altschuld and Witkin advise, "We cannot emphasize too strongly that assessment is not complete unless plans are made to use the information in a practical way." 19 This move to action may include changes to the curriculum and/or its academic processes or changes to the assessment plan itself. ${ }^{32}$ So far, the cycles of the model have been described and the elements of each cycle have been defined. The remainder of this paper documents a program's utilization of the model to assess student decision making about patient/client management.

\section{MODEL IMPLEMENTATION}

The model was implemented in a graduate physical therapist education program located in a Midwest public university in the USA. During the implementation, there were 5 full-time faculty. The assessment occurred during the last year granting a master of physical therapy (MPT) degree before transitioning to a doctoral-granting degree (DPT). The program faculty considered this data collection year a pivotal one to determine any major curriculum needs because content and process decisions for the new DPT program would likely endure for years.

The program's mission is Contextualized Professional Decision Making with program goals coalescing in the three areas of context, profession, and decision making. Decision making, as one of the three hallmarks of the program mission, was identified by program faculty as a priority for program assessment. The curriculum goal "decision making" was also congruent with professional and university expectations. ${ }^{33,34}$ Thus, decision making was an important area for many stakeholders of the program and reinforced the faculty decision to prioritize it for assessment.

The faculty had used a guiding document of the physical therapy profession to develop the curricula related to decision making about patient management. The Normative Model of Physical Therapist Education identifies eight patient/client management expectations. ${ }^{33}$ Each of the eight expectations (Screening, Examination, Evaluation, Diagnosis, Prognosis, Plan of care, Intervention, and Outcomes assessment) requires complex decision making evident in the extensive definitions provided in the Normative Model. Collectively these eight patient/client management expectations represent the program's definition of clinical decision making. One of the eight, Intervention, serves as the exemplar for implementation and evaluation of the model described in this paper. The definition of Intervention provided by the Normative Model shows the expectation for Intervention goes well beyond the skill of delivering procedures and techniques to patients. Educational outcome examples for Intervention provided by the Normative Model state that the graduate "documents all necessary information in an organized manner that demonstrates sound clinical decision making; tailors interventions with consideration for the patient client/family situation and resources; and modifies interventions based on progress toward patient client goals and outcomes." Decision making is a requisite for attaining these outcomes.

(c) The Internet Journal of Allied Health Sciences and Practice, 2014 
At the time of the MPT to DPT transition, the faculty wanted assessment data that would help them identify if they were making progress toward the goals for decision making. The authors proposed the use of the model in order to move assessment from unfocused data collection to a systematic needs assessment approach. Beginning with the "what is," faculty reviewed existing survey data collected from students at graduation and discovered on a recent year that some students perceived their achievement slightly below entry-level on content related to Intervention. (Entry-level achievement is the threshold the program set as minimal standard for items on the survey.) Anecdotally, faculty realized that this student perception of achievement was congruent with comments occasionally received on course evaluations, another program data source. Therefore, faculty felt a potential problem (a gap between "what is" and "what should be") might exist, but the magnitude and explanation needed definition, prompting faculty to discuss general questions about the problem.

During a curriculum review meeting, the faculty generated questions about teaching content and teaching methods that could be contributing to students' perception of a gap in their decision making abilities. However, faculty felt student input was also needed to gain depth of understanding about the potential problem. In addition, student input into curricular decisions was not widely utilized despite the university's mission of student-centered learning. This was further impetus to focus an initial question on student perception of learning. At this point, the faculty was prepared to initiate into the model's cyclical process using a focused question.

\section{First Question - Decision Cycle}

The program's focused question became: Do our students perceive any critical needs in meeting the program's goal for decision making? The model required the faculty to choose a method for investigating the question. The Critical Needs Quadrant Method was selected because it affords both a visual representation of the identified need to facilitate faculty discussion and provides a need index to quantify the need. The need index gives the oft-ignored discrepancy data essential to needs assessment techniques. ${ }^{18,21}$

To implement the Critical Needs Quadrant Method, a data collection tool was needed to obtain data from the identified data source: students near graduation. Faculty developed a self- report survey which asked about students' perception of achievement and importance on each of the eight patient/client management expectations included in the Normative Model. On the survey tool, perceived achievement is measured on a 1-5 ordinal scale where a score of 1 indicates well below, 3 at entrylevel and 5 well above entry-level achievement. Perceived importance is measured on a 1-5 scale where a score of 1 indicates least important and a score of 5 indicates most important. A section of this measurement tool is shown in Figure 3 . All students completed the tool during a capstone experience held by the program just prior to graduation.

Figure 3. Measurement Tool

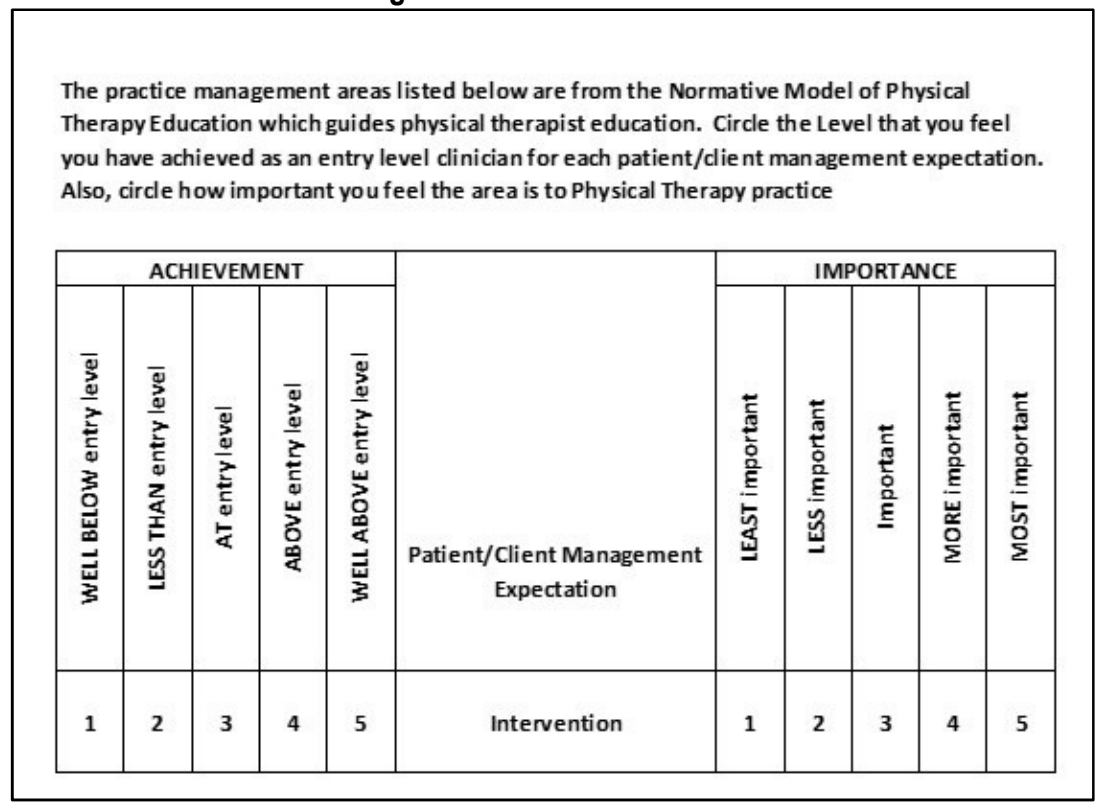

(C) The Internet Journal of Allied Health Sciences and Practice, 2014 
The class average for achievement and importance was calculated for each of the eight expectations representing decision making. These averaged values were then graphed with achievement on the horizontal axis and importance on the vertical axis (Figure 4). A value of 4.0 for each axis divides the graph into four quadrants. The level of 4.0 was chosen by faculty because it exceeds the program and accreditation standard of entry-level and can alert toward critical needs well before the minimum expectation of entry-level achievement (3.0) is not met. The four quadrant areas on the graph correspond to high importance/high achievement, low importance/low achievement, low importance/high achievement, and high importance/low achievement.

Figure 4. Critical Need Quadrant, Capstone Data

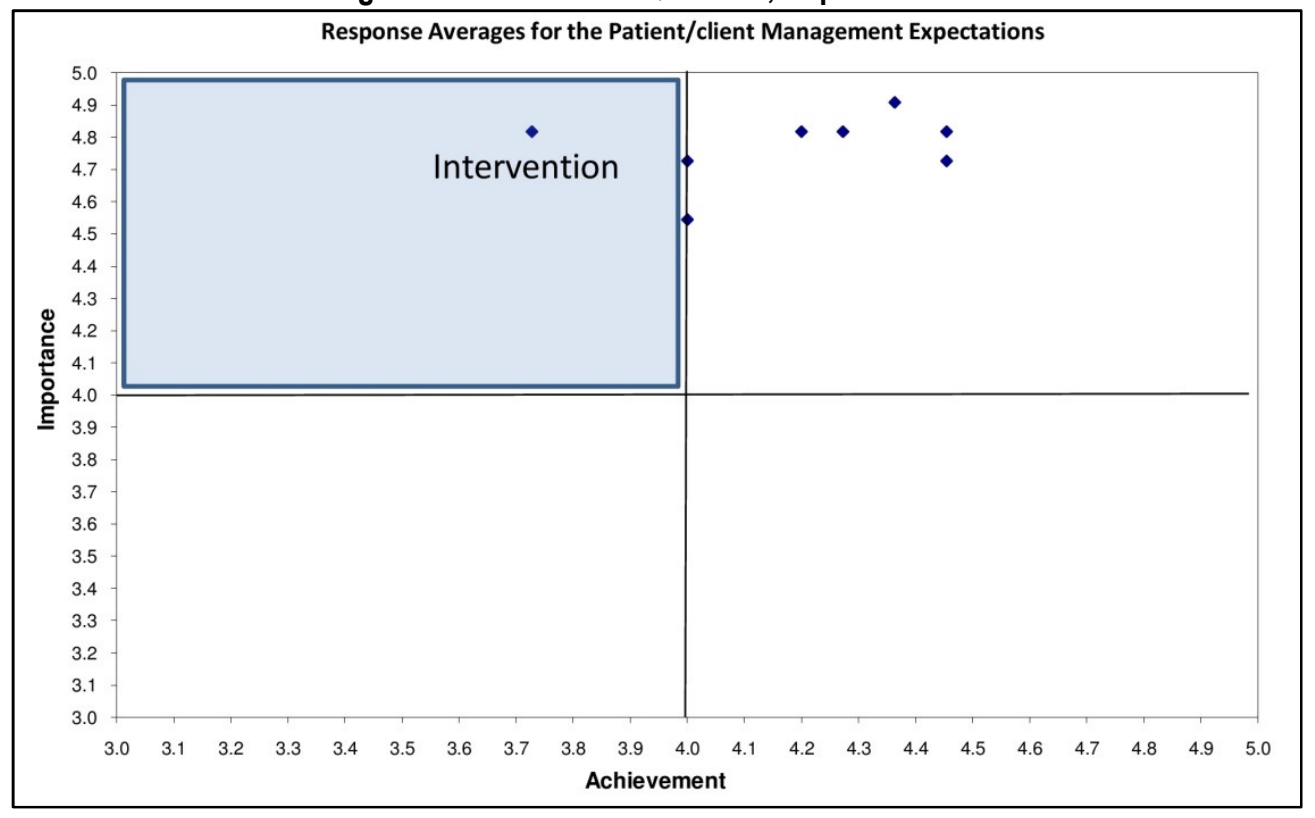

One desires to have high achievement in areas of greatest importance; therefore, the quadrant depicting low achievement/high importance is the area of greatest concern. Patient/client management expectations that graph into the low achievement high importance quadrant are flagged as critical need for further program assessment. Figure 4 shades the critical need quadrant for the patient/client management data collected from students at capstone. While not addressed in this paper, the other quadrants are also informative and may direct faculty discussions about achievement and importance. ${ }^{20}$ For example, if patient/client management expectations graph into the high achievement-high importance quadrant, these expectations may need to be carefully monitored to maintain such high levels. Expectations that graph into the low importance quadrants may warrant comparison to faculty identification of importance, and if discrepant, students can be re-directed by faculty emphasis or affective learning activities to increase student value of the expectation. The quadrant graph is a visual representation that allows quick identification of critical need when an expectation graphs into the high importance but low achievement quadrant area.

In addition to visualization of critical need via the critical need quadrant, a need index is calculated for each patient/client management expectation by subtracting the average perceived achievement from the average perceived importance. Referencing back to the model's needs assessment framework, the "what is" is student achievement and "what should be" is importance, both reflected in the need index. The assumption of the importance value is that student achievement is desired to be highest in areas of greatest importance. A large need index for any patient/client management expectation would indicate a priority need to investigate the discrepancy between "what is" and "what should be." The maximum need index possible would be calculated as a 4 if students rated achievement as a one and importance as a five. An index value of 4 would indicate the furthest from ideal, the greatest underachievement in an area of greatest importance.

On the quadrant graph, only the patient/client practice management expectation of Intervention graphed into the critical need quadrant (Figure 4). The remaining seven expectations did not graph into this quadrant. The need index for Intervention calculated to 1.1, the highest index of all the expectations. The significance of the critical need index for Intervention warranted the faculty's decision to further analyze the data about this patient/client expectation area. Closer analysis of the need index found that while students perceived an acceptable level of achievement (3.7 on 5 point scale), their perceived level of importance for Intervention was extremely high (4.8 on 5 point scale). The very highly perceived importance caused the expectation of 
Intervention to be identified as a critical need, not a low level of achievement. The identification of a critical need from one data source, while informative, does not necessitate curriculum change, especially in the light of an explaining hypothesis of excessive perception of importance. Faculty discussion about the finding raised the question of whether students who had not yet practiced were identifying importance higher than they might as practicing clinicians.

At this point faculty had data from implementing the first Question cycle of the model and they were prompted to enter the Decision cycle. The faculty had three options in the Decision cycle (Figure 2): revise question, raise a new question, or make a change. Faculty discussion resulted in the determination that the need was not yet well understood and made the decision to delay any program changes based on this data alone. Discussion also resulted in the decision against moving on to Raising New Questions but to choose Revising Questions so that clarifying information about the practice expectation Intervention could be gained. Following the model's arrow from the Decision cycle element Revising Questions prompted the faculty to re-enter the Question cycle using a revised but related question (see Figure 2 for arrow).

\section{Second Question-Decision Cycle}

Based on assessment data from the first iteration of the model showing high importance associated with the practice area intervention, faculty revised the assessment question to become "Do student-perceived curriculum needs differ from graduation to one year after graduation?" This question would help confirm or negate the hypothesis of excessive perception of importance for the practice area of intervention. Other methods could have been used to answer this revised question, but faculty wanted to compare new findings directly to the existing critical need data. Faculty chose the same Critical Need Quadrant method used during the first iteration of the Question cycle. However, a different program data source was needed because of the focus of the revised question. That source was identified as students one year post-graduation. Therefore, the same cohort group one year after graduation completed the same self-report survey tool. The graphical display and need index value was calculated the same as for the capstone data. This allowed comparison of findings from the same cohort group over time. The one-year graduate data indicated that Intervention still fell in the critical need quadrant of the graphical display and the need index value calculated to 1.6. Analysis of the data showed that graduates with one year of experience still perceived achievement at an acceptable level (3.4 on the 1-5 scale) but perceived importance at the highest level ( 5 on the 5 point scale). It still appeared that the high level of importance was contributing most to the identification of a critical need rather than low achievement. To further investigate or triangulate the findings, faculty compared the student perception of critical need to other existing program data.

One item of existing data was the national licensure examination which includes content about interventions. The pass rate of our graduates indicated the program was achieving this standard at or above the national level. Additionally, graduate perception of achievement was above the program's established threshold of 3.0 (entry-level achievement). The investigation of data so far found student and graduate perceived critical need was not consistent with other program data. Entering the Decision cycle of the model a second time again prompted faculty to consider alternatives to making program changes based on these incongruent findings. The model again led faculty to choose to engage in another iteration of the question-decision cycle.

\section{Third Question-Decision Cycle}

Using the model to enter a third question-decision cycle, faculty considered another element of the question cycle, communities of interest. Collecting data from non-students would determine whether student perceptions were congruent with others important to the program. Faculty discussion identified supervisors of graduates as a community of interest. Supervisors, being experienced professionals, would have knowledge of interventions and their importance and as employers of program graduates, are important stakeholders. Once the community of interest was identified, the model's decision cycle prompted the faculty to either identify a new question or formulate a revised question. Faculty again decided on Revised Questions rather than a new question so that resulting data could be directly compared.

The revised question became "Are supervisors' perceptions congruent with student perception of critical need in decision making?" The perception of supervisors about graduate achievement and importance of the patient/client management expectations was collected via a similar tool to that used for self-report by graduates. The Normative Model patient/client expectations were imbedded in an existing survey sent to supervisors of graduates one year post-graduation. The supervisor was asked to identify how well the graduate functions as an entry-level clinician on each of the patient/client management expectations and to identify the importance of each expectation. The same ordinal 1-5 measurement scale was used on the supervisor's data collection tool as is used for the graduate perception of achievement and importance. Supervisor perception of graduate achievement and importance data were graphically displayed identically to that for graduate data and the need index value was calculated.

(c) The Internet Journal of Allied Health Sciences and Practice, 2014 
The supervisor data for the cohort group did not place the patient/client management expectation of Intervention in the critical need quadrant. The need index value for the supervisor data calculated to 0.30 , indicating little gap between perceived importance and achievement. Further investigation found supervisor perception of graduate achievement to be 3.7, very similar to the graduates' perception. However, the supervisors perceived importance of the Intervention expectation to be 4.0, which is less important than the graduates at both the capstone and at one-year post-graduation data collection. Less perceived importance by the supervisors moved decision making related to Intervention out of the critical need quadrant for this program community of interest.

Program faculty now had three data findings, two of which identified a perceived critical need, both being from student/graduate perceptions but not substantiated by their supervisors or other existing program data. Faculty discussed all findings and now felt they had enough information to utilize the Decision cycle element Program Change and make a decision for action rather than enter another iteration of the question-decision cycle. The faculty decided the appropriate action was to augment content about interventions within existing courses rather than larger actions such as a course addition, course re-sequencing, or instructor changes. Content augmentation was based on prior course evaluations indicating students had difficulty choosing priority interventions for early, middle, or late stages of care as well as knowing when to progress the interventions. Faculty provided learning activities focused on these aspects of decision making about interventions.

Faculty had utilized the model to continue questioning about the program need until the element Program Change in the Decision cycle was appropriate. Changes that the faculty made were not substantive such as the addition of a course because all three findings from the Question cycles confirmed a high level of achievement. Briggs et al advocates "quality driven" program change that "may lead to either major or minor changes, or even to informed decisions to maintain the status quo" but should be based on "data from multiple sources imbedded into an ongoing assessment plan." ${ }^{35}$ Faculty were confident in the decision to make content augmentation rather than more substantive but also potentially disruptive changes because they also decided to make decision making about patient/client management part of the annual assessment process. Therefore, the patient/client management area of intervention would continue to be monitored. The model's use convinced faculty that assessment could be a valuable use of their time and effort and result in quality information for program improvement.

\section{EVALUATION OF THE MODEL}

The purpose of using the model was to guide our faculty toward linking assessment to program goal(s), engage faculty, identify needs, be responsive to diverse stakeholders, and create an iterative process. The model was successful in prompting assessment activities at our program to move from an undefined process to one that connected curricular goals to relevant assessment questions. Assessment that had been a top-down administrative process was now based on faculty questions and therefore rooted in the relevance of faculty's day-to-day tasks. Further, assessment now stimulated faculty discussion about current findings and future questions to be pursued. Using the model, faculty were guided to employ a useful and measureable method to define the need (the Critical Need Quadrant Method) and identify the appropriate level of change needed. The assessment process kept faculty from overreacting with substantive changes that would have been unwarranted and costly. The model reminded faculty to include stakeholders that can provide diverse perspectives to the program resulting in more fully informed decisions about change. The cyclical model highlighted an iterative process and prompted faculty to ask more refining questions resulting in an ongoing data-driven program assessment process.

Evaluation of the model with the above criteria met faculty and program expectations for a more coherent assessment process. However, the most critical evaluative criteria would require re-entering the question cycle to ultimately ask, "Did the decisions prompted by the model result in program improvement?" In fact, utilizing the same methodology, the capstone data from the following two years' classes showed that the patient/client management expectation of Intervention remained in the critical need quadrant of the graph; however, the need index narrowed from 1.1 to .93 and then to .81 . The narrowing of the index indicated less need, or a smaller gap, convincing evidence that the course-level content change was effective and in the right direction. Faculty continued to emphasize content related to Interventions. In the most recent year's data, Intervention has moved out of the critical need quadrant into the high achievement/high importance quadrant (Figure 5). 
Figure 5. Critical Need Quadrant, Most Recent Data

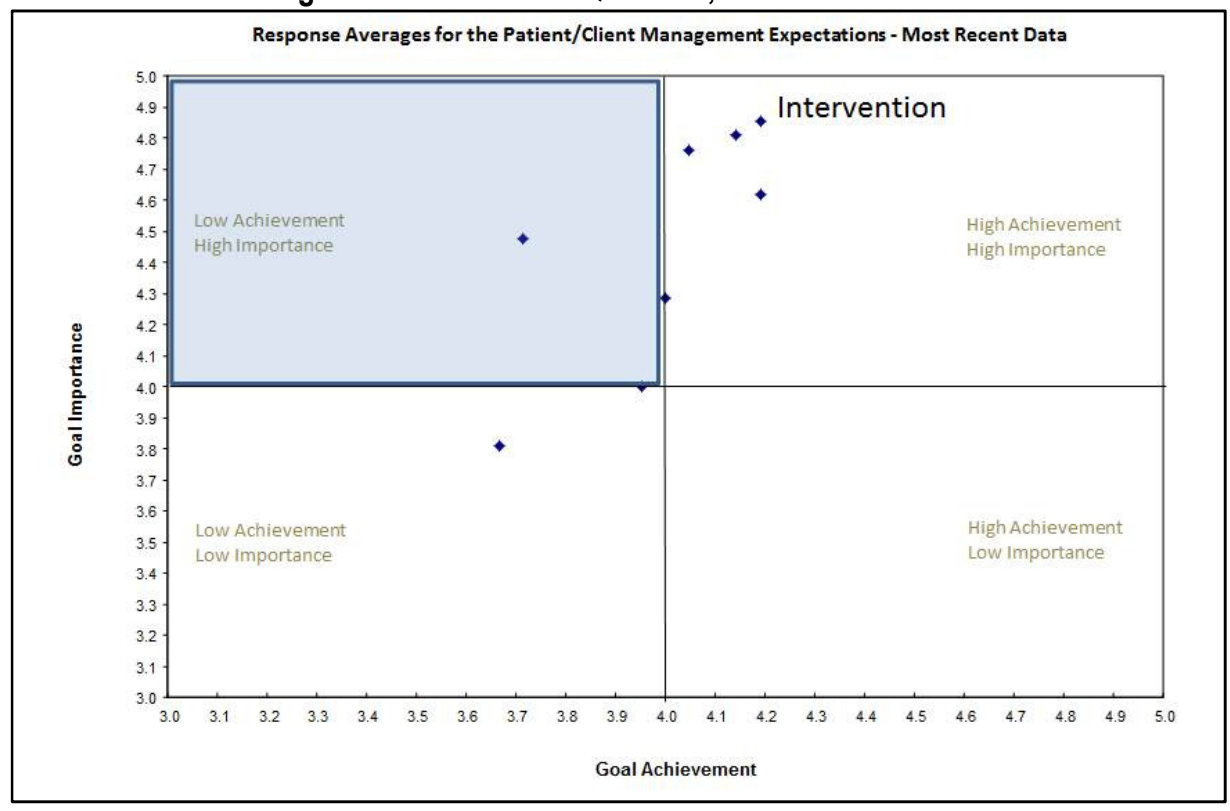

The efficacy of the model is that the degree of course revision made was consistent with the employers' and other existing program data that indicated students were meeting practice demands. The model is important by virtue of allowing the faculty to gauge the level of change needed. The model prompted decisions to continue data collection until the need was better understood. Finally, the model prompted the decision for focused course-level changes but with ongoing assessment. Program improvement depends on both effective improvement and the deliberative decision not to disrupt the integration of the existing curriculum without data-driven evidence to help faculty design and implement appropriate changes.

Had the critical need remained or worsened, the faculty could question, asking, "What do students perceive as content or learning activities needed?" The model would then prompt the faculty to choose a method specific for answering this question. For example, additional assessment of students' perception about Intervention using focus group discussions could have yielded their suggestions for specific learning strategies to address either achievement or importance.

\section{DISCUSSION AND CONCLUSIONS}

The model was successfully implemented in our particular academic institution where specific characteristics may have influenced its effectiveness. At the time of data collection described in this paper, the five faculty had 7 to 15 years of teaching experience and three faculty had formal training in assessment via their terminal degrees. All five of the faculty had been at the university during the graduate curriculum development and so were very familiar with the curriculum and the mission hallmark "decision making" on which the curriculum was based. The efficacy for the model for one program has been demonstrated, but the model needs further evaluation, especially applied to other programs with various faculty profiles.

Resources required for implementation of our model include a program chairperson incorporating the model process into ongoing faculty discussions. Further resources of time and effort (including that of support staff) are needed for data collection, although it sometimes can be accomplished at minimal cost. The data collection method described in this paper was simply incorporated into an already existing graduate and supervisor survey. Utilizing existing information or opportunities to interact with student supervisors, employers, guest lecturers, and alumni to collect data over time further minimizes costs and maintains communication about program progress with interested stakeholders. ${ }^{26,27}$

The benefits of the model are its heuristic nature (simple, directed toward solution), its recursive loop from faculty-developed questions to data driven discussion which revises further questions, and the multiplicity of input provided by assessment methods, sources of data, and communities of interest. Use of the model leads to a deeper understanding of problems and solutions and results in educational program improvement.

Another value of the model is its inherent flexibility that allows incorporation of important consensus standards from health science professions into the model. Implementation of the model using a guiding document from the physical therapy profession 
allows for generalizability to all accredited physical therapy programs. Other health science education programs have their own guiding documents that can be easily incorporated.

In summary, the proposed assessment model provides a recursive process for posing substantive program questions relating to goals and facilitates collecting data from diverse methods, program data sources, and communities of interest to define the gap between where a program is and where it wants to be. The two cycles of the model perpetuate an iterative assessment process via questions and decisions meant to drive thoughtful, informed program change.

\section{REFERENCES}

1. Ewell PT. Can assessment serve accountability? It depends on the question. In Burke JC. Achieving Accountability in Higher Education (pp.104-124). San Francisco, CA: Jossey-Bass, 2005.

2. Maki PL. Assessing for Learning: Building a Sustainable Commitment Across the Institution. Sterling, VA: Stylus Publishing, 2004.

3. Cahalin LP, Matsuo Y, Collins SM, Matsuya A, Caro F. Educational and professional issues in physical therapy - an international study. Physiotherapy Theory and Practice. 2008;24(5):344-56. [PMID:18821441]

4. Eder D. Accredited programs and authentic assessment. In Palomba CA, Banta TW, Eds. Assessing Student Competence in Accredited Disciplines (pp.199-216). Sterling, VA: Stylus Publishing, 2001.

5. Smith MJ. Program Evaluation in the Human Services. NY, NY: Springer, 1990.

6. Palomba CA, Banta TW, Eds. Assessing Student Competence in Accredited Disciplines. Sterling, VA: Stylus, 2001.

7. Tippett S. Program impact of student outcome assessment in physical therapy education. Journal of Physical Therapy Education. 2006;20(2):38-47.

8. Boucher B. Program assessment in physical therapy education: The transition to use of new criteria. Journal of Physical Therapy Education. 1999;13(1):18-27.

9. Banta TW, Lund JP, Black KE, Oblander FW. Assessment in Practice: Putting Principles to Work on College Campuses. San Francisco, CA: Jossey-Bass, 1996.

10. Haviland D, Shin S, Turley S. Now I'm ready: The impact of a professional development initiative on faculty concerns with program assessment Innovative Higher Education. 2010;35(4):261-75.

11. Walvoord BE. Assessment Clear and Simple: A Practical Guide for Institutions, Departments, and General Education. San Francisco: Jossey-Bass, 2004.

12. Astin AW. Assessment for Excellence: The Philosophy and Practice of Assessment and Evaluation in Higher Education. American Council on Education. Phoenix AZ: Oryx Press, 1991.

13. Welsh JF, Metcalf J. Faculty and administrative support for institutional effectiveness activities: A bridge across the chasm? The Journal of Higher Education. 2003;74(4):445-68.

14. Schilling KM, Schilling KL. Proclaiming and sustaining excellence: Assessment as a faculty role. ASHE-ERIC Higher Education Report. 1998;26(3). (Washington DC: The George Washington University. Graduate School of Education and Human Development)

15. Wehlburg CM. Closing the Feedback Loop Is Not Enough: The Assessment Spiral. Assessment Update. 2007;19(2):1-15.

16. Wehlburg CM. Promoting Integrated and Transformative Assessment: A Deeper Focus on Student Learning. San Francisco: Jossey Bass, 2008.

17. Banta TW. Double Loop Learning in Assessment. Assessment Update. 2011;23(3):3.

18. Altschuld JW, Kumar DD. Needs Assessment, an Overview. Thousand Oaks, CA: Sage Publications, 2010.

19. Altschuld JW, Witkin BR. From Needs Assessment to Action. Thousand Oaks, CA: Sage Publications, 1999.

20. Altschuld JW, White JL. Needs Assessment, Analysis and Prioritization. Thousand Oaks, CA: Sage Publications, 2010.

21. Witkin BR, Altschuld JW. Planning and Conducting Needs Assessments: A Practical Guide. Thousand Oaks, CA: Sage Publications, 1995.

22. Kaufman R, English FW. Needs Assessment: Concept and Application. Englewood Cliffs, NJ: Educational Technology Publications, 1979.

23. Ratnapalan S, Hilliard RI. Needs assessment in postgraduate medical education: A review. Medical Education, Online. 2002;7:8. http://www.med-ed-online.org/f0000040.htm, Accessed 8/05/2014.

24. Altschuld JW, King JA, Stevahn L, Kumar DD, Eastmond Jr N. Needs Assessment Kit. Thousand Oaks, CA: Sage Publications, 2010.

25. Ding CS. Measurement issues in designing and implementing longitudinal evaluation studies. Educational Assessment, Evaluation and Accountability. 2009;21:155-71.

26. Norcini JJ, McKinley DW. Assessment methods in medical education. Teaching and Teacher Education. 2007;23(3):23950. 
27. Boyce EG, Long TJ. Finding and using readily available sources of assessment data. American Journal of Pharmacy Education. 2008;72(5):102. [PMID: 19214256]

28. Vassar M, Wheeler DL, Davison M, Franklin J. Program evaluation in medical education: An overview of the utilizationfocused approach. Journal of Educational Evaluation for Health Professions. 2010;7:1. DOI 10.3352/jeehp.2010.7.1. [PMID: 20559515]

29. Wehlburg CM. Assessing learning: from accountability to transformation. New Directions for Teaching and Learning. 2010;123:45-50. DOI 10.1002/tt.408

30. Gibson KA, Boyle P, Black DA, Cunningham M, Grimm MC, Mc-Neil HP. Enhancing evaluation in an undergraduate medical education program. Academic Medicine. 2008;83(8):787-93. [PMID: 18667897]

31. Dikstra J, Van der Vleuten CP, Schuwirth LW. A new framework for designing programmes of assessment. Advances in Health Science Education. 2010;15(3):379-93. [PMID: 18667897]

32. American Physical Therapy Association (APTA). Outcome Assessment in Physical Therapy Education, 2008. Available at: http://www.apta.org/uploadedFiles/APTAorg/Educators/Assessments/Outcomes Assessment/OutcomesAssessment_Full.p dffsearch=\%22Outcome Assessment in Physical Therapy Education 2008\%22, Accessed 8/05/2014.

33. American Physical Therapy Association (APTA). A Normative Model of Physical Therapist Professional Education, 2004, Alexandria, VA.

34. Threlkeld AJ, Jensen GM, Royeen CB. The clinical doctorate: a framework for analysis of physical therapist education. Physical Therapy. 1999;79(6):567-81. [PMID: 10372868]

35. Briggs CL, Stark JS, Rowland-Poplawski J. How do we know a "continuous planning" academic program when we see one? The Journal of Higher Education. 2003;74(4):361-85. 
APPPENDIX A

Needs Assessment. Analysis and Prioritization, Table 5.1: Methods Often Used for Prioritizing Needs

\begin{tabular}{|c|c|c|c|}
\hline Method & Basic Description & Advantages & Disadvantages \\
\hline $\begin{array}{c}\text { Group } \\
\text { Discussion }\end{array}$ & $\begin{array}{l}\text { Based on what has been } \\
\text { learned in the needs } \\
\text { assessment process, the } \\
\text { NAC* uses a discussion to } \\
\text { arrive at a consensus }\end{array}$ & $\begin{array}{l}\text { Easy to do } \\
\text { Flows out of previous work and } \\
\text { understanding of needs data } \\
\text { Fits many situations } \\
\text { A quick way to see if there is a } \\
\text { general agreement in the NAC } \\
\text { Relatively fast procedure }\end{array}$ & $\begin{array}{l}\text { Not particularly explicit with regard to } \\
\text { criteria for choices } \\
\text { Discussions can be dominated by a } \\
\text { few influential members } \\
\text { Probably doesn't align with cases } \\
\text { where needs are complex or } \\
\text { consequences are great } \\
\text { May be harder to justify priorities if } \\
\text { they are questioned }\end{array}$ \\
\hline $\begin{array}{c}\text { Rank- } \\
\text { Ordering }\end{array}$ & $\begin{array}{l}\text { If the list of needs is not } \\
\text { long, NAC members rank- } \\
\text { order usually in terms of } \\
\text { perceived importance }\end{array}$ & $\begin{array}{l}\text { Easy to do } \\
\text { Works well for shorter lists of needs } \\
\text { Many variations of rank-ordering } \\
\text { procedures can be used (see Book } 1 \\
\text { in the KIT) } \\
\text { Relatively fast procedure } \\
\text { May permit seeing if there are } \\
\text { disagreeing subgroups in the NAC }\end{array}$ & $\begin{array}{l}\text { Often done of the basis of one } \\
\text { criterion (importance) } \\
\text { Too simplistic for complex needs } \\
\text { Usually subtle and different meanings } \\
\text { ascribed by rankers to the one } \\
\text { criterion } \\
\text { With many needs (>15) the rankers } \\
\text { may have to use the rule of three or } \\
\text { first selecting a subset of needs and } \\
\text { then rank-ordering the items in it }\end{array}$ \\
\hline $\begin{array}{l}\text { Zero Sum } \\
\text { Game } \\
\text { Structure }\end{array}$ & $\begin{array}{l}\text { Reviewers are assigned } \\
\text { points (perhaps 10) and } \\
\text { allot them to needs as } \\
\text { appropriate } \\
\text { Often points or symbols } \\
\text { for them (stars, colors) are } \\
\text { done in a group setting for } \\
\text { needs posted on walls }\end{array}$ & $\begin{array}{l}\text { If done in a group setting with color- } \\
\text { or otherwise-coded symbols, it is } \\
\text { easy to see subgroup patterns and } \\
\text { resolve differences } \\
\text { May require a rule such as only so } \\
\text { many points can be assigned to one } \\
\text { need } \\
\text { Novelty and fun dimension than can } \\
\text { enliven groups }\end{array}$ & $\begin{array}{l}\text { Despite the fun aspect the points are } \\
\text { allotted based on one criterion } \\
\text { (importance) } \\
\text { May not deal well with complex types } \\
\text { of needs } \\
\text { Without rules sometimes members of } \\
\text { a group will place an undue number } \\
\text { of points on their favored need }\end{array}$ \\
\hline $\begin{array}{l}\text { Using Two or } \\
\text { more Criteria } \\
\text { (simple } \\
\text { format) }\end{array}$ & $\begin{array}{l}\text { The NAC or a similar } \\
\text { group looks at each need } \\
\text { in terms of criteria such as } \\
\text { importance to the } \\
\text { organization and feasibility }\end{array}$ & $\begin{array}{l}\text { Moderately easy to implement } \\
\text { Requires group members to consider } \\
\text { more criteria } \\
\text { Many criteria can be used } \\
\text { Can be done with yes/no responses } \\
\text { or Likert scales for the criteria }\end{array}$ & $\begin{array}{l}\text { While a step beyond the techniques } \\
\text { above it may not go far enough with } \\
\text { regard to complex needs } \\
\text { Importance and feasibility criteria } \\
\text { probably have to be broken into } \\
\text { subparts }\end{array}$ \\
\hline
\end{tabular}




\begin{tabular}{|c|c|c|c|}
\hline Method & Basic Description & Advantages & Disadvantages \\
\hline $\begin{array}{l}\text { Multiple } \\
\text { Criteria with } \\
\text { a Screening } \\
\text { Mechanism }\end{array}$ & $\begin{array}{l}\text { Multiple criteria are } \\
\text { identified and then rank- } \\
\text { ordered } \\
\text { Each potential need is } \\
\text { looked at in terms of the } \\
\text { most important criterion } \\
\text { first, and the ones that } \\
\text { pass through that screen } \\
\text { are examined in regard } \\
\text { to the other criteria } \\
\text { (screens) in order of their } \\
\text { importance } \\
\text { Those that pass through } \\
\text { all the screens would be } \\
\text { thought of as priorities } \\
\text { (essentially a sifting } \\
\text { process) }\end{array}$ & $\begin{array}{l}\text { More complex process that forces } \\
\text { deeper thinking on the part of NAC } \\
\text { members } \\
\text { Ordering of criteria appears to be a } \\
\text { good idea; some criteria are just more } \\
\text { important than others } \\
\text { Would rapidly reduce the number of } \\
\text { needs for consideration } \\
\text { For some areas (health, education) } \\
\text { may work well }\end{array}$ & $\begin{array}{l}\text { May fractionate the decision-making } \\
\text { process because criteria often should } \\
\text { be considered jointly instead of in } \\
\text { isolation to each other } \\
\text { As with any procedure, when it } \\
\text { becomes more complicated } \\
\text { implementation may be more difficult } \\
\text { Not commonly observed in the } \\
\text { conduct of needs assessments }\end{array}$ \\
\hline $\begin{array}{l}\text { Importance } \\
\text { and } \\
\text { Feasibility } \\
\text { Ratings (more } \\
\text { complex) }\end{array}$ & $\begin{array}{l}\text { While other approaches } \\
\text { deal with importance and } \\
\text { feasibility, Sork (1998) } \\
\text { divided the two criteria into } \\
\text { logical subcategories for } \\
\text { use in selecting the } \\
\text { highest-priority needs } \\
\text { Each importance and } \\
\text { feasibility subcriterion is } \\
\text { rated on a 1-5 scale, } \\
\text { which subsequently leads } \\
\text { to summed group ratings } \\
\text { for the two categories }\end{array}$ & $\begin{array}{l}\text { Requires that the committee rate } \\
\text { each need candidate carefully } \\
\text { Deeper thought about prioritizing } \\
\text { needs } \\
\text { Additional criteria can be brought in } \\
\text { and rated in the same manner as } \\
\text { suggested by Altschuld and Witkin } \\
\text { (2000) } \\
\text { Other ways of doing the ratings are } \\
\text { possible } \\
\text { For complex and sensitive situations, } \\
\text { the procedure provides a solid base } \\
\text { for establishing priorities }\end{array}$ & $\begin{array}{l}\text { Most groups have not done ratings } \\
\text { like these and are unfamiliar with } \\
\text { them } \\
\text { Some individuals find this to be } \\
\text { complicated and tedious } \\
\text { Can be laborious, especially if a large } \\
\text { number of needs are to be sorted } \\
\text { through and dwindled down }\end{array}$ \\
\hline $\begin{array}{l}\text { Same as } \\
\text { Previous } \\
\text { Category } \\
\text { with Risk } \\
\text { Assessment } \\
\text { Formally } \\
\text { Included }\end{array}$ & $\begin{array}{l}\text { Internal and external risks } \\
\text { of attending or not } \\
\text { attending to needs are } \\
\text { added to the process }\end{array}$ & $\begin{array}{l}\text { Makes the risk factor explicit in the } \\
\text { prioritization decision } \\
\text { May be particularly necessary in } \\
\text { some needs assessments such as in } \\
\text { health and public health } \\
\text { preparedness (natural disasters, } \\
\text { epidemics, terrorists attacks, etc.) }\end{array}$ & $\begin{array}{l}\text { Adds another level of complication to } \\
\text { prioritization } \\
\text { Slows down prioritization } \\
\text { Some aspects of risk may be quite } \\
\text { subjective in judgment }\end{array}$ \\
\hline
\end{tabular}




\begin{tabular}{|c|c|c|c|}
\hline Method & Basic Description & Advantages & Disadvantages \\
\hline $\begin{array}{c}\text { Prioritization } \\
\text { Embedded in } \\
\text { Strategic } \\
\text { Planning }\end{array}$ & $\begin{array}{l}\text { Technique is called } \\
\text { Casual-Utility Decision } \\
\text { Analysis, or CUDA (Leigh, } \\
\text { 2000) } \\
\text { An NAC or other similarly } \\
\text { constituted body would be } \\
\text { charged with completing a } \\
\text { four-celled grid with one } \\
\text { dimension consisting of } \\
\text { assets/liabilities } \\
\text { (strengths/weaknesses) } \\
\text { and the other being } \\
\text { internal/external locus } \\
\text { Each cell in the resultant } \\
\text { grid is subdivided into } \\
\text { three columns--issues, } \\
\text { estimated costs and value } \\
\text { (utility), and control } \\
\text { (causality) }\end{array}$ & $\begin{array}{l}\text { Pushes the NAC to be very analytical } \\
\text { in its thought processes } \\
\text { Use of the four cells and the } \\
\text { subcategories in them is an excellent } \\
\text { mechanism for engaging a planning } \\
\text { group in discussion } \\
\text { If the group was moderately large it } \\
\text { could be split into smaller groups, } \\
\text { which would complete the worksheets } \\
\text { independently (it would be of interest } \\
\text { and importance to see if they had } \\
\text { related or identical ideas) } \\
\text { Clever and novel way of attacking } \\
\text { prioritization }\end{array}$ & $\begin{array}{l}\text { Somewhat more involved and } \\
\text { complex than a number of other } \\
\text { techniques and may tax the patients } \\
\text { of the NAC } \\
\text { As descried by Leigh (2000) and } \\
\text { others there may be a tendency to } \\
\text { attribute failure more to external than } \\
\text { internal sources } \\
\text { Will most likely require two passes to } \\
\text { do, the first being done by individuals } \\
\text { and the second by groups in a } \\
\text { collective fashion }\end{array}$ \\
\hline
\end{tabular}

*NAC - Needs Assessment Committee

(C) Needs Assessment. Analysis and prioritization by Altschuld, James W. Reproduced with permission of Sage Publications, Inc in the format Republish in other published product via Copyright Clearance Center. 
APPENDIX B

Needs Assessment. Analysis and Prioritization, Figure 5.2: Using Multiple Criteria to Prioritize Needs

\begin{tabular}{|c|c|c|c|c|}
\hline $\begin{array}{c}\text { Need } \\
\text { Candidate }\end{array}$ & $\begin{array}{c}\text { Importance } \\
\text { (Yes/No) }\end{array}$ & $\begin{array}{c}\text { Feasibility } \\
\text { (Yes/No) }\end{array}$ & $\begin{array}{c}\text { Cost Factor } \\
\text { (High/Low) }\end{array}$ & $\begin{array}{c}\text { Risk } \\
\text { (High/Low) }\end{array}$ \\
\hline 1 & & & & \\
\hline 2 & & & & \\
\hline 3 & & & & \\
\hline 4 & & & & \\
\hline$n$
\end{tabular}

(C) Needs Assessment. Analysis and Prioritization by Altschuld, James W. Reproduced with permission of Sage Publications, Inc in the format Republish in other published product via Copyright Clearance Center. 